\title{
Research on Promotion of Emergency Rescue Strategy of General Aviation for Earthquake Disaster in Mountain Area
}

\author{
Liang Zhang \\ Guangzhou Civil Aviation College, China
}

Keywords: emergency rescue, general aviation, mountain area.

\begin{abstract}
This paper analyzes the influencing factors of earthquake emergency rescue of general aviation in mountain area, the relevant knowledge of operational research is applied, the influencing factors of emergency rescue are analyzed and evaluated by analytic hierarchy process; according to the analysis results, the strategies and methods of how to comprehensively improve the earthquake emergency rescue level of general aviation in mountain area in China are proposed.
\end{abstract}

\section{Analysis of Influencing Factors of Earthquake Emergency Rescue of General Aviation in Mountain Area}

General aviation emergency rescue uses the related rescue force general aviation after accidents and disasters occurred, and scientifically and reasonably plan to carry out the rescue through the known information. General aviation plays a "last mile" role in earthquake disaster rescue in mountain area, so to speak. The earthquake emergency rescue of general aviation in mountain area mainly consists of three main elements: emergency rescue system, emergency rescue process, external factors in rescue [1].

(1) Analysis of Rescue System.

The emergency rescue system mainly consists of five parts: emergency rescue command center, rescue equipment, rescue personnel, communication and intelligence, and logistics support and maintenance.

Emergency rescue command center is an operation organization, which starts from the perspective of personnel configuration, features and functions, in order to improve the rescue effectiveness, cooperate with the ground troops in the execution of the rescue task, coordinate and command various kinds of rescue resources; rescue equipment is vehicle, rescue equipment and airborne equipment for quick and effective emergency rescue, and can quickly reach the disaster relief site, and have search, rescue, supply, transport, medical treatment and other corresponding basic ability; rescue personnel are professional personnel, which are engaged in rescue and related work in emergency rescue; communication and intelligence are to realize communication among rescue sites, rescue teams and command centers in the execution of task and provide real-time and effective information for rescue teams; logistical support and maintenance are to provide corresponding support for the rescue teams that carry out the task.

(2) Analysis of Rescue Process.

During the rescue process, the following four stages are generally experienced: event occurrence and response, plan formulation, implementation and operation, finish and end.

The occurrence and response of the event, after the earthquake disaster occurred, the information gathering of disaster area and the actions taken in the early stage of the accidents are generally the key whether the victims are able to get help or not; rescue plan formulation, implementation of the rescue is the largest and most complicated part in the whole process, it is necessary to draw up a good plan for different rescue targets, and this plan is usually need to be repeated; rescue implementation and operation, although a good rescue plan has drawn up, rescue personnel and equipment also has the safeguard, but all are based on the theoretical feasibility, the actual implementation of the rescue will still be affected by the uncertain factors of the site, so in order to carry out rescue, it is necessary to be prepared; rescue finish and end, when the rescue is carried out to a certain extent, the headquarters issued an order to end the rescue according to the actual situation. 


\section{(3) Analysis of External Factors}

The emergency rescue of earthquake disaster is actually in competition with nature, especially the secondary disasters and weather changes after the earthquake occurred, the force majeure factors will certainly cause great bad impact on the rescue. All external factors are interlarded in each rescue link, and even the pre-set rescue plan will need to be re-determined due to the effect of external factors. If these external factors can be taken into account in advance, the effect brought by external factors can be avoided to a certain extent and do less unnecessary work.

\section{Hierarchy Analysis and Evaluation of the Influencing Factors of General Aviation Emergency Rescue}

(1) Establishment of Hierarchical Structure Model

Based on the above influencing factor analysis of general aviation emergency rescue, and the analytic hierarchy process (AHP), YAAHP software is used, and four secondary indexes, 15 three-level indexes is used to build the divergent type hierarchical structure model, as shown in Figure.[2].



Figure 1 hierarchy structure diagram of general aviation emergency rescue

The A represent general aviation emergency rescue of target layer, B1, B2, B3, B4 represent rescuers in basic layer, rescue equipment, external environment, organization and management, $\mathrm{C} 1$, C2, C3, 4 C, C5, C6, C7, C8, C9, C10, C11, C12, 13 C, 14 C, C15, from left to right to represent personnel support, technological level, operation ability, physical and mental qualities, general aircraft, airborne equipment, rescue support equipment, maintenance support facilities, public opinion, weather conditions, terrain conditions, emergency rescue command center, material guarantee supply, formulation of laws and regulations, general aviation contingency plans of index layer, respectively.

(2) Hierarchical Analysis Calculation and Sorted Result

1. Evaluation scale and Judgment Matrix.

Delphi method is used to take the form of anonymous questionnaire survey to get the experts ' opinion from all industries. According to their own situation level, totally 10 experts are selected to participate in the questionnaire, including two civil aviation professional teachers, two navigation front line workers, two fire department personnel, two seismological bureau staffs, two students of this major, the table below is the experts' scoring statistical table. 
Table 1 experts' scoring statistical table

\begin{tabular}{|c|c|c|c|c|c|}
\hline & P1 & $\mathrm{P} 2$ & P3 & $\ldots \ldots$ & $\mathrm{P} 10$ \\
\hline B1 & 9 & 7 & 8 & $\ldots \ldots$ & 6 \\
\hline C1 & 2 & 6 & 7 & $\ldots \ldots$ & 3 \\
\hline C2 & 9 & 7 & 8 & $\ldots \ldots$ & 8 \\
\hline C3 & 8 & 5 & 6 & $\ldots \ldots$ & 8 \\
\hline C4 & 7 & 8 & 6 & $\ldots \ldots$ & 6 \\
\hline B2 & 8 & 9 & 6 & ...... & 8 \\
\hline C5 & 8 & 8 & 5 & ...... & 8 \\
\hline C6 & 5 & 7 & 6 & $\ldots \ldots$ & 8 \\
\hline C7 & 6 & 9 & 7 & ...... & 7 \\
\hline C8 & 4 & 8 & 7 & $\ldots \ldots$ & 6 \\
\hline B3 & 6 & 6 & 9 & ....... & 7 \\
\hline C9 & 4 & 5 & 3 & ...... & 2 \\
\hline C10 & 9 & 7 & 9 & $\ldots \ldots$ & 8 \\
\hline C11 & 6 & 6 & 8 & $\ldots \ldots$ & 7 \\
\hline B4 & 7 & 5 & 7 & $\ldots \ldots$ & 9 \\
\hline C12 & 4 & 5 & 7 & $\ldots \ldots$ & 7 \\
\hline C13 & 6 & 6 & 6 & ...... & 8 \\
\hline C14 & 8 & 8 & 8 & $\ldots \ldots$ & 8 \\
\hline C15 & 7 & 6 & 7 & $\ldots \ldots$ & 9 \\
\hline
\end{tabular}

According to the scoring condition of the experts, the 1-9 ration scale of Saaty is used to mark and conduct the quantitative treatment of the relative importance degree, form the judgment matrix is formed, the quantitative formula is as follows.

$$
\begin{aligned}
& a_{(i, j)}=\left\{\begin{array}{l}
|b \mathrm{i}-b j|+1\left(b_{i}>b_{j}\right) \\
\frac{1}{|b \mathrm{i}-b j|+1}
\end{array}\right. \\
&\left(b_{i} \leq b_{j}\right) \mathrm{i}=1,2,3 \cdots \cdots \cdot \mathrm{n} ; \mathrm{j}=1,2,3 \cdots \cdots \cdot \mathrm{n}
\end{aligned}
$$

Table 2 assignment table of relative importance degree

\begin{tabular}{cc}
\hline scale & definition \\
\hline 1 & factor $\mathrm{i}$ is as important as factor $\mathrm{j}$ \\
5 & factor $\mathrm{i}$ is slightly more important than factor $\mathrm{j}$ \\
7 & factor $\mathrm{i}$ is relatively important than factor $\mathrm{j}$ \\
9 & factor $\mathrm{i}$ is more important than factor $\mathrm{j}$ \\
$2,4,6,8$ & factor $\mathrm{i}$ is absolutely important than factor $\mathrm{j}$ \\
reciprocal of the above numerical values & reciprocal of the relative importance degree which factor i compared with factor $\mathrm{j}$
\end{tabular}

Due to too much data, it is difficult to enumerate them; the following is detailed calculation process of score condition of P1. The formula $(2,1)$ is used for quantitative calculation of the relative important degree and form the judgment matrix, bi and bj are the evaluation results of expert P1 on the general aviation emergency rescue, similarly, ci and cj is the evaluation results of B in B - C matrix, ai is the relative important degree assignment after experts ' quantitative scoring. The above table 2-2 gives the meaning of the relative importance degree of the two indexes. The quantitative results and judgment matrix are shown in the table below. 
Table 3 judgment matrix and relative importance degree quantization table of A-B layer

\begin{tabular}{ccccc}
\hline A & B1 & B2 & B3 & B4 \\
\hline B1 & 1 & 2 & 4 & 3 \\
B2 & $1 / 2$ & 1 & 3 & 2 \\
B3 & $1 / 4$ & $1 / 3$ & 1 & $1 / 2$ \\
B4 & $1 / 3$ & $1 / 2$ & 2 & 1 \\
\hline
\end{tabular}

Table 4 judgment matrix and relative importance degree quantization table of B1-C layer

\begin{tabular}{ccccc}
\hline B1 & C1 & C2 & C3 & C4 \\
\hline C1 & 1 & $1 / 8$ & $1 / 7$ & $1 / 6$ \\
C2 & 8 & 1 & 2 & 3 \\
C3 & 7 & $1 / 2$ & 1 & 2 \\
C4 & 6 & $1 / 3$ & $1 / 2$ & 1 \\
\hline
\end{tabular}

Table 5 judgment matrix and relative importance degree quantization table of B2-C layer

\begin{tabular}{ccccc}
\hline B2 & C5 & C6 & C7 & C8 \\
\hline C5 & 1 & 4 & 3 & 5 \\
C6 & $1 / 4$ & 1 & $1 / 2$ & 2 \\
C7 & $1 / 3$ & 2 & 1 & 3 \\
C8 & $1 / 5$ & 2 & $1 / 3$ & 1 \\
\hline
\end{tabular}

Table 6 judgment matrix and relative importance degree quantization table of B3-C layer

\begin{tabular}{cccc}
\hline B3 & C9 & C10 & C11 \\
\hline C9 & 1 & $1 / 6$ & $1 / 3$ \\
C10 & 6 & 1 & 4 \\
C11 & 3 & $1 / 4$ & 1 \\
\hline
\end{tabular}

Table 7 judgment matrix and relative importance degree quantization table of B4-C layer

\begin{tabular}{ccccc}
\hline B4 & C12 & C13 & C14 & C15 \\
\hline C12 & 1 & $1 / 3$ & $1 / 5$ & $1 / 4$ \\
C13 & 3 & 1 & $1 / 3$ & $1 / 2$ \\
C14 & 5 & 3 & 1 & $1 / 2$ \\
C15 & 4 & 2 & 2 & 1 \\
\hline
\end{tabular}

After using the formula to calculate, the experts ' scoring is quantized as the relative important degree assignment, the above five judgment matrix A, B1, B2, B3, B4 are constructed, next, sorted calculation and consistency check can be carried out.

(2) Hierarchical Single Sort and Consistency Check

Characteristic root method: the weight vector $\omega=\left(\omega_{1}, \omega_{2}, \cdots \omega_{n}\right)^{T}$ is multiplied by the right weight ratio matrix A.

$$
A \omega=\lambda_{\max } \omega
$$

The constant $\lambda_{\max }$ is the maximum characteristic root of the judgment matrix; this maximum characteristic value exists and is unique, in addition, the component of non-zero vector is positive, and the weights obtained are normalized. Taking matrix $\mathrm{A}$ as an example, the calculation process is as follows.

The elements in A are normalized, namely.

$$
\bar{a}_{i j}=a_{i j} / \sum_{k=1}^{n} a_{k j}, i, j=1,2, \cdots n
$$

The row on the same line of A matrix is added after the normalization process, namely: 


$$
\tilde{\omega}_{i}=\sum_{j=1}^{n} \bar{a}_{i j}, i=1,2, \cdots n
$$

Divide the added vector by n, namely

$$
\omega_{i}=\tilde{\omega} / n
$$

Calculate the largest characteristic root:

$$
\lambda_{\max }=\frac{1}{n} \sum_{i=1}^{n} \frac{(A \omega)_{i}}{\omega_{i}}
$$

According to the above steps, the 8 table is obtained.

Table 8 the weight calculation table of A matrix

\begin{tabular}{ccccccc}
\hline A & B1 & B2 & B3 & B4 & $\tilde{\omega}_{i}$ & $\omega_{i}$ \\
\hline B1 & 0.4800 & 0.5217 & 0.4000 & 0.4615 & 1.8632 & 0.4658 \\
B2 & 0.2400 & 0.2608 & 0.3000 & 0.3077 & 1.1086 & 0.2771 \\
B3 & 0.1200 & 0.0870 & 0.1000 & 0.0770 & 0.3840 & 0.0960 \\
B4 & 0.1600 & 0.1305 & 0.2000 & 0.1538 & 0.6443 & 0.1611 \\
$\sum \bar{a}_{i j}$ & 1 & 1 & 1 & 1 & & \\
\hline
\end{tabular}

b1-b4 is the normalized processing result in the above table, $\omega_{i}$ is the characteristic vector, namely weight of each index. Then the maximum characteristic root $\lambda_{\max }$ is calculated, and the maximum characteristic root $\lambda_{\max }$ is the necessary parameter of consistency check. The following formula (2-7) is used to calculate the $A \omega$ in formula (2-6),

$$
A \boldsymbol{\omega}=\left(\begin{array}{llll}
a_{11} & a_{12} & a_{13} & a_{14} \\
a_{21} & a_{22} & a_{23} & a_{24} \\
a_{31} & a_{32} & a_{33} & a_{34} \\
a_{41} & a_{42} & a_{43} & a_{44}
\end{array}\right)\left(\begin{array}{c}
\omega_{1} \\
\omega_{2} \\
\omega_{3} \\
\omega_{4}
\end{array}\right)
$$

$a_{i j}$ is the quantized results without normalized processing in the formula, and the following results are obtained after calculation.

$$
(A \omega)_{i}=\left(\begin{array}{llll}
1.8873 & 1.1202 & 0.3854 & 0.6469
\end{array}\right)
$$

The calculation results are put into the formula (2-6), and the maximum characteristic root is obtained $\lambda_{\max }=4.0310$.

Through the above calculation process, the characteristic vector of matrix A and the maximum characteristic root are obtained.

$$
\begin{aligned}
& \omega_{i}=\left(\begin{array}{llll}
\omega_{1} & \omega_{2} & \omega_{3} & \omega_{4}
\end{array}\right)=\left(\begin{array}{llll}
0.4658 & 0.2771 & 0.0960 & 0.1611
\end{array}\right) \\
& \lambda_{\max }=4.0310
\end{aligned}
$$

In order to verify the reliability of the calculation results, the judgment matrix is needed for a consistency check in the next step. The consistency index is defined as,

$$
\text { C.I. }=\left(\lambda_{\max }-n\right) /(n-1)
$$




$$
C . R .=C . I . / R . I \text {. }
$$

In formula (2-9), C.I. is the consistency index, R.I. is the random consistency index, and the specific numerical value is shown in Table 2-9. The consistency ratio, when $C \cdot R .=0$, matrix $\mathrm{A}$ is the complete consistency matrix; when $C . R .<0.1$, the matrix A is the satisfying consistency matrix; When $C . R .>0.1$, the matrix A does not meet the consistency. In general, when the matrix meets the satisfying consistency, $\lambda_{\max }$ is slightly greater than the matrix order $n$.

Table 9 R.I. random consistency index diagram

\begin{tabular}{ccccccc}
\hline order & 3 & 4 & 5 & 6 & 7 & 8 \\
\hline R.I. & 0.58 & 0.89 & 1.12 & 1.24 & 1.32 & 1.41 \\
\hline
\end{tabular}

The $\lambda_{\max }=4.0310$, R.I. $=0.89$ are put into formula (2-8) and formula (2-9), get C.R. $=0.0116<0.1$ is obtained after calculation, so the matrix calculation results of A-B are consistent with the satisfying consistency check, and the data can be affirmed to be completely reasonable. Similarly, according to the calculation process of matrix A, matrix B1, B2, B3 and B4 are carried out hierarchical single order and consistency check by using formula (2-3) to (2-9). The results are as follows:

Table 10 matrix single order and consistency check diagram

\begin{tabular}{cccccc}
\hline B1 & C1 & C2 & C3 & C4 & $\omega_{i}$ \\
\hline C1 & 0.0455 & 0.0638 & 0.0393 & 0.02710 & 0.0439 \\
C2 & 0.3636 & 0.5106 & 0.5490 & 0.4865 & 0.4774 \\
C3 & 0.3182 & 0.2553 & 0.2745 & 0.3243 & 0.2931 \\
C4 & 0.2727 & 0.1702 & 0.1372 & 0.1622 & 0.1856 \\
\hline
\end{tabular}

Maximum characteristic root $\lambda_{\max }=4.0858$; consistency index C.I. $=0.0286$; check results are C.R. $=0.0321<0.1$.

Table 11 B2 matrix single order and consistency check diagram

\begin{tabular}{cccccc}
\hline B2 & C5 & C6 & C7 & C8 & $\omega_{i}$ \\
\hline C5 & 0.5607 & 0.5333 & 0.6270 & 0.4545 & 0.5423 \\
C6 & 0.1402 & 0.1333 & 0.1034 & 0.1818 & 0.1397 \\
C7 & 0.1869 & 0.2667 & 0.2069 & 0.2727 & 0.2333 \\
C8 & 0.1121 & 0.0667 & 0.069 & 0.0909 & 0.0847 \\
\hline
\end{tabular}

Maximum characteristic root $\lambda_{\max }=4.0512$; consistency index C.I. $=0.0171$; check results is C.R. $=0.0192<0.1$. 
Table 12 B3 matrix single order and consistency check diagram

\begin{tabular}{ccccc}
\hline B3 & C9 & C10 & C11 & $\omega_{i}$ \\
\hline C9 & 0.1000 & 0.1177 & 0.0625 & 0.0934 \\
C10 & 0.6000 & 0.7059 & 0.7500 & 0.6853 \\
C11 & 0.3000 & 0.1765 & 0.1875 & 0.2213 \\
\hline
\end{tabular}

The maximum characteristic root $\lambda_{\max }=3.0541$; consistency index C.I. $=0.0271$; check result is C.R. $=0.0521<0.1$.

Table 13 B4 matrix single order and consistency check diagram

\begin{tabular}{cccccc}
\hline B4 & C12 & C13 & C14 & C15 & $\omega_{i}$ \\
\hline C12 & 0.0769 & 0.0526 & 0.0566 & 0.1111 & 0.0743 \\
C13 & 0.2308 & 0.1579 & 0.0943 & 0.2222 & 0.1763 \\
C14 & 0.3846 & 0.4737 & 0.2830 & 0.2222 & 0.3409 \\
C15 & 0.3077 & 0.3158 & 0.5660 & 0.4444 & 0.4085 \\
\hline
\end{tabular}

Maximum characteristic root $\lambda_{\max }=4.1627$; consistency index C.I. $=0.0286$; check result is C.R. $=0.0609<0.1$.

(3) Total Order of Hierarchy and Consistency Check

In the consistency test of total order, C.I. is the consistency index of total, R.I. is average random consistency index of total order, and C.R. is the consistency ratio of total order. The formula is as follows,

$$
\begin{gathered}
\text { C.I. }=\sum_{i=1}^{n} \omega_{i} C_{._{i}} \\
\text { R.I. }=\sum_{i=1}^{n} \omega_{i} R ._{\cdot_{i}} \\
\text { C.R. }=\text { C.I./R.I. }
\end{gathered}
$$

Arrange the single order results in 2.4 and carry out the total order. Table 2-14 is obtained, 
Table 14 total order diagram of expert P1 levels

\begin{tabular}{|c|c|c|c|c|c|}
\hline & B1 & B2 & B3 & B4 & $\mathrm{C}$ total order of factors \\
\hline$\omega_{i}$ & 0.4658 & 0.2771 & 0.096 & 0.1611 & \\
\hline C. I. & 0.0286 & 0.0171 & 0.0271 & 0.0286 & \\
\hline C1 & 0.0439 & & & & 0.0204 \\
\hline C2 & 0.4774 & & & & 0.2224 \\
\hline C3 & 0. 2931 & & & & 0.1365 \\
\hline $\mathrm{C} 4$ & 0.1856 & & & & 0.0865 \\
\hline C5 & & 0.5423 & & & 0.1503 \\
\hline C6 & & 0.1397 & & & 0.0387 \\
\hline $\mathrm{C} 7$ & & 0.2333 & & & 0.0647 \\
\hline C8 & & 0.0847 & & & 0.0235 \\
\hline C9 & & & 0.0934 & & 0.009 \\
\hline C10 & & & 0.6853 & & 0.0658 \\
\hline C11 & & & 0.2213 & & 0.0212 \\
\hline $\mathrm{C} 12$ & & & & 0.0743 & 0.012 \\
\hline $\mathrm{C} 13$ & & & & 0.1763 & 0.0284 \\
\hline C14 & & & & 0.3409 & 0.0549 \\
\hline C15 & & & & 0.4085 & 0.0658 \\
\hline
\end{tabular}

The data in above table are put into the formula 2-10 to 12 for the total order consistency test, and get C.I. $=0.02527$, R.I. $=0.8602$, C.R. $=0.0294<0.1$. The consistency check is check means, which is used to determine whether the calculation of whole model has error and avoid decision-making mistakes. According to the test results, total order results of hierarchy are consistent.

(4) Calculation Results and Weight Order

Through the average treatment of the weight ratio of the experts, the weight of the influencing factors of the general aviation emergency rescue is obtained. As shown in the following table. 
Table 15 weight order diagram of influencing factors of emergency rescue of general aviation

\begin{tabular}{ccccccccc}
\hline index & C1 & C2 & C3 & C4 & C5 & C6 & C7 & C8 \\
\hline $\begin{array}{c}\text { weight } \\
\text { order }\end{array}$ & $\begin{array}{c}0.0243 \\
14\end{array}$ & $\begin{array}{c}0.1027 \\
2\end{array}$ & $\begin{array}{c}0.0815 \\
6\end{array}$ & $\begin{array}{c}0.0405 \\
12\end{array}$ & $\begin{array}{c}0.1402 \\
1\end{array}$ & $\begin{array}{c}0.0832 \\
4\end{array}$ & $\begin{array}{c}0.0709 \\
8\end{array}$ & $\begin{array}{c}0.0389 \\
13\end{array}$ \\
\hline index & C9 & C10 & C11 & C12 & C13 & C14 & C15 \\
\hline $\begin{array}{c}\text { weight } \\
\text { order }\end{array}$ & $\begin{array}{c}0.0128 \\
15\end{array}$ & $\begin{array}{c}0.0728 \\
7\end{array}$ & $\begin{array}{c}0.0429 \\
11\end{array}$ & $\begin{array}{c}0.0647 \\
9\end{array}$ & $\begin{array}{c}0.0549 \\
10\end{array}$ & $\begin{array}{c}0.0816 \\
5\end{array}$ & $\begin{array}{c}0.0882 \\
3\end{array}$ & \\
\hline
\end{tabular}

It can be seen from the table above that the order of these influencing factors are: C5 navigation aircraft, C2 technology level, C15 navigation emergence plan, C6 airborne equipment, C14 formulation of laws and regulations, C3 operation ability, C10 weather condition, C7 rescue auxiliary equipment, C12 emergency rescue command center, C13 material support and supply, C11 terrain conditions, C4 physical and mental factors, C8 maintenance and support facilities, C1 personnel support, C9 public opinion.

\section{Improve the Level and Strategy of Earthquake Emergency Rescue of General Aviation in Mountain Area}

According to the hierarchy order results above, the corresponding strategy which this papers put forward mainly open from general aircraft, rescue personnel' technical operation ability, navigation emergency plans, formulation of laws and regulations, and material support and supply five aspects.

(1) Strengthen the Allocation of General Aircraft

Heavy-lift helicopter and large helicopter can accomplish lifting heavy equipment, mass material and rescue personnel transport, transfer of victim and trapped persons, etc.; the medium-sized helicopter can complete rescue of the trapped persons and so on, and it is a kind of multi-functional model; small and light helicopter can complete supply and distribution, disaster detection, passenger transport and other tasks.

(2) Improve Technical Operational Capacity.

From the current science and technology development level, the subject of implement rescue is still human. Ignoring the effect caused by external factors, the accident in the rescue and the victims' secondary injury are often caused by rescuers ' mistakes. Only through a large number of training can strengthen the technical operational ability of personnel, the rescue can completed under the circumstance of poor environment, insufficient information, various task and high intensity.

(3) Formulate Emergency Plans for Navigation.

The formulation of navigation emergency plans make rescue department can respond quickly according to the regulations of the plans the first time, make the navigation department can quickly control and use existing resources when the mountain earthquake happened, and orderly and effectively carry out rescue activities.

(4) Perfect Laws and Regulations

The enactment and perfection of laws and regulations provide the legal basis for the vague standard of contradiction, conflict, responsibility and behavior rule. The perfection of laws and regulations should have following three aspects: first, specify the legal relationship between the rescue departments and forces and the government departments; secondly, revise the problem of the difficult approval, long time and complicated flight route under the current regulations; third, integrate air rescue into our emergency rescue system, perfect the existing laws and regulations, the operation procedures, disposal rules and relevant support standards of the air rescue forces in the face of sudden disasters are standardized.

(5) Reasonable Planning of Emergency Material

The distribution and deployment of emergency material have sudden, mandatory, stage, and weak economy features in the earthquake disaster, in order to avoid vacuum of response phase of emergency material occur in the disaster relief, first, the central authorities, province, prefecture-level 
cities, county, district and other places set up emergency material storage center, meanwhile considering the characteristics of mountain earthquake disasters and terrain where earthquake frequently happened, according to the of capacity of local air rescue teams, comprehensive material transport systems are established and cooperate with logistics enterprise to carry out material support;

Second, modern emergency material management information systems are establish and put into use, modern science and technologies are used to make the system have the function of check the use condition of emergency material, displaying quantity in stock of all kinds of materials, record of material input-output, the scheme formulation of transporting material to disaster area, information exchange superior and subordinate, equal department, and other functions; third, establish emergency material distribution center and plan material distribution path, the flat structure is used to carry out material transportation, materials of storage center are transported to distribution center and then uniformly distribute according to the requirements of the disaster area, and improve the rescue efficiency.

\section{References}

[1]. Chen Hong, Song Fuxi, Wen Ming, et al. Research on Earthquake Emergency Rescue Standard System and Its Key Standards [J], China Safety Science Journal, 2012, 22(7):164-170.

[2]. http://www.doc88.com/p-7078698098547.html 